\title{
Future prospects for use of fibrinolysis inhibitors
}

\author{
M VERSTRAETE \\ From the Centre for Thrombosis and Vascular Research, Department of Medical Research, \\ University of Leuven, Belgium
}

Fibrinolysis inhibitors are of value in the control of severe overdosage with fibrinolytic agents. The discussion so far has been mainly on the use of fibrinolytic inhibitors to reduce or arrest local bleeding in the absence of an increase in systemic fibrinolytic activity. There are still other clinical applications of antifibrinolytic drugs that are worth mentioning, since further research in these areas may prove rewarding.

Hereditary and non-hereditary angioneurotic oedema

Hereditary angioneurotic oedema is an inborn defect in the synthesis of a serum $\alpha_{2}$-globulin which is primarily an inhibitor of the activation of $C^{\prime} 1 \mathrm{~s}$ subcomponent of the first component of complement. ${ }^{1}$ In consequence the enzymatic activity of $\mathrm{C}^{\prime} 1$-esterase is uncontrolled. The missing neuraminoglycoprotein is also capable of blocking the action of plasma kallikrein and PF/Dil, a plasma factor which increases cutaneous vascular permeability. ${ }^{2} \mathrm{C}^{\prime} 1$ inactivator is in addition a plasmin substrate.

The oedema of subcutaneous and submucous tissues of hereditary angioneurotic oedema is well controlled by synthetic inhibitors such as epsilon-aminocaproic acid or tranexamic acid. Since C1 inhibitor activity and $\mathrm{C} 4$ concentrations are not influenced by these drugs it has been suggested that they do not act on $\mathrm{Cl}$ but on some further step or that they may have to do with the release of a vasoactive kinin from the human second component of complement once it has been cleaved by $\mathrm{C} 1$-esterase. ${ }^{3}$ The mode of action of tranexamic acid seems therefore to differ from that of androgens, which do augment synthesis of $\mathrm{C} 1$ inhibitor. ${ }^{5}$

Spontaneous idiopathic (non-hereditary) angioneurotic oedema has been successfully treated with synthetic inhibitors. Possibly some patients with recurrent idiopathic angioneurotic oedema develop a low threshold in their kinin-release mechanisms, perhaps owing to an acquired defect of an inhibitor for which tranexamic acid can be substituted. ${ }^{6}$ This threshold could also be affected by the balance of circulating adrenaline and 'stress hormones'.
Patients with idiopathic recurrent angioneurotic oedema without an obvious allergic basis or identifiable precipitating cause should therefore be studied in greater detail, and if the oedema and obstruction to the airway are not controlled by antihistamines a trial with tranexamic acid may be justified. It should be noted, however, that a double-blind cross-over study, lasting 9 weeks in 17 patients with chronic urticaria and slightly lowered $\mathrm{Cl}$-esterase inhibitor concentrations, did not result in a significant improvement in symptoms. ${ }^{\text {? }}$

\section{Blocking of complement activation in SLE}

Circulating immune complexes are often present in autoimmune diseases such as systemic lupus erythematosus (SLE) and could be responsible for the activation of complement, the cause of tissue lesions. It is indeed known that complexes containing IgG and IgM activate the first component by binding its $\mathrm{Cl}_{\mathrm{q}}$ subunit to a site located in the $\mathrm{Fc}$ region of the immunoglobulin. Immune complexes were also shown to induce the platelet release reaction, even in the absence of complement, in man and to stimulate indirectly the activation of the fibrinolytic system. In addition plasmin has been shown to enhance the C3 amplification loop of the complement cascade.

Nymand and Dyerberg ${ }^{8}$ therefore speculated that a synthetic plasmin inhibitor such as tranexamic acid could impair the activation of the complement system and inhibit the progress of the tissue lesions in autoimmune diseases. Preliminary clinical evidence is still anecdotal and should be pursued.

\section{Inhibition of neutrophil proteases}

Human neutrophil granulocytes contain several proteases. Within the slow fraction of azurophil cytoplasmic granules there are two metallo-proteinases, collagenases (MW 76000), and a serine proteinase elastase (MW 34000$) .910$ The collagenases cleave collagen molecules in solution into the two specific fragments and also fibrin. The elastases not only hydrolyse native elastin but also 
have broad substrate activity (fibrinogen, light chains of immunoglobulins, and several coagulation factors as well as $\mathrm{C} 3$ ). These enzyme activities are inhibited by plasma $\alpha_{1}$-antitrypsin and $\alpha_{2}$-macroglobulin and chloromethyl ketone inhibitors. The release of lysosomal proteases from granulocytes on phagocytosis of particles such as zymosan and immune complexes is most intriguing. ${ }^{11} 12$

The elastases may aid in the lysis of bacterial walls by attacking susceptible linkages in the peptide bridges of peptidoglycans or in other structural wall proteins investing the bacterial wall envelope and so co-operate with the neutrophil lysozyme endoglycanohydrolase. Still another physiological role of the elastase may lie in the digestion of bacterial protoplast proteins once cell walls have been broken. In pathological conditions one could speculate that neutrophil elastase may attack elastin fibres or connective tissues in a variety of tissues-for example, in arteries (in arteritis), lung elastin (in emphysema), and cartilage proteoglycans (in inflammatory joint disorders).

Future studies should delineate the interactions of neutrophil proteases, their tissue targets, and their endogenous inhibitors in an effort to understand the mediation of tissue damage by these cells in man.

\section{Contraception by inhibition of acrosin}

The acrosome, a cape-shaped organel at the head of spermatozoa, contains acrosin, a proteinase with trypsin-like specificity. Present evidence suggests that activation of the zymogen precursor occurs ky several steps of sequential proteolytic cleavages and involves the splitting of an arginyl-X bond. The major role of this proteinase appears to be the digestion of a small oblique tunnel through the zona pellucida, a dense glycoprotein capsule surrounding the ovum, allowing the spermatozoon to enter the perivitelline space where fusion of the plasma membranes of the male and female gametes occurs. ${ }^{13}$ Trypsin inhibitors will inhibit the dissolution of the zona pellucida. ${ }^{14} 15$

Acrosomal proteinase is specific for the peptide and ester bonds of lysine and arginine. The physicochemical, enzymatic, structural, and antigenic properties of acrosin are strikingly similar to those of pancreatic trypsin. There is a physiological relationship between this proteinase and proteinase inhibitors in the human seminal plasma, cervical mucus, and oviduct fluid. ${ }^{1617}$ The function of the acrosin inhibitors in the male is mainly that of rapidly neutralising the enzymatic potential of acrosin whenever the enzyme is activated or liberated at the wrong place - that is, before mating or captivation of the spermatozoa in the female reproductive tract.
Tranexamic acid is known to diffuse into the prostate and seminal vesicles from where it is excreted into the semen. Epsilon-aminocaproic acid given to male rats results in a reversible $50 \%$ reduction in fertility. Tranexamic acid given to healthy men volunteers decreased the fibrinolytic activity of the semen but did not change the in-vitro sperm migration in cervical mucus collected at the time of ovulation. ${ }^{18}$

\section{Prevention of lysis of exogenous fibrin}

Neurosurgeons are experimenting with fibrin sutures for peripheral nerves. They use human fibrinogen ( 5 to $10 \%$ ) which is clotted on the spot with thrombin. Addition of inhibitors of fibrinolysis, either locally or systemically, prevents the early lysis of the fibrin sutures. ${ }^{19}$ The same technique can be used for fixing fascia transplants-for example, in operations in the ear where suturing is difficult or impossible. Graft survival for more than six months and improved hearing resulted in 31 cases of myringoplasty when clotted fibrinogen was used under cover of tranexamic acid compared with 30 similar operations without fibrin suture. ${ }^{20}$

Lyophilised fibrinogen has been used to close vesicovaginal fistulae after gynaecological procedures such as hysterectomy or radiotherapy for carcinoma of the cervix. Since these fistulae are often difficult to treat plasma fractions rich in fibrinogen clotted with thrombin are used to assist tissue adhesion. Tranexamic acid is given to prevent lysis of the fibrin plug. The fibrin forms a supporting framework for migrating fibroblasts and developing capillary buds. ${ }^{21}$

\section{Other inhibitors of fibrinolysis}

Clinical experience so far is mainly limited to two groups of fibrinolytic inhibitors, the $\omega$-aminocarboxylic acids and aprotinin. There are, however, other groups of serine protease inhibitors which may become clinically important.

The best known synthetic inhibitors of fibrinolysis are lysine; epsilon-aminocaproic acid, or 6-aminohexanoic acid ;22 cyclic aminocarboxylic acid (trans4-aminomethyl cyclohexane carboxylic acid, or AMCHA, tranexamic acid); p-aminomethyl benzoic acid (PAMBA); 4-aminomethyl-bicyclo-2,2,2-octane carboxylic acid (AMBOCH) ${ }^{23}$ and related $\omega$-aminocarboxylic acids. They all appear to inhibit plasminogen activation by tissue activator (blood activator) due to interference as a result of a displacement of plasminogen from the fibrin surface. The molecular basis is due to complementary structures in the plasminogen molecule called lysine-binding sites and 
complementary sites in the fibrin molecule. ${ }^{24} 25$

A second well-known fibrinogen inhibitor is aprotinin, the basic protease inhibitor from bovine organs. Aprotinin has a broad inhibition specificity since it forms equimolar complexes with trypsin, chymotrypsin, plasmin, and glandular kallikreins. Their toxicity is low and with a molecular weight of 6500 antigenicity is not a problem. Unfortunately the polypeptide aprotinin has to be given intravenously. It has been used mainly in acute pancreatitis. Several clinical trials did not show any benefit from the drug and gradually it ceased to be used routinely. Derivatives of benzamidine are competitive inhibitors of trypsin but also of plasmin, thrombin, factor $\mathrm{Xa}$, and other enzymes with trypsin-like activities. ${ }^{23}$ These low molecular weight inhibitors could become clinically relevant. Synthetic peptides, or arginine chloromethyl ketone, are inhibitors of serine proteases. They act as affinitylabelling compounds since their amino-acid sequences are similar to those at the cleavage site of the physiological substrate. Presumably they alkylate the active centre histidine. ${ }^{26} 27$

Tripeptide aldehyde analogs of specific sequences may act as selective competitive inhibitors of certain serine proteases. D-Phe-Pro-Arg-H is a potent reversible inhibitor of thrombin. ${ }^{28}$ Similar studies on tri- and tetrapeptides suggest that molecular manipulation of lower molecular weight peptide analogues of serine proteases may result in the design of a potent inhibitor of thrombin or of activated factor $\mathrm{Xa}$, or both.

Okamoto $^{29}$ has recently reported on a new synthetic inhibitor of thrombin, a benzopiperidine derivative[3-methyl-8-[sulfonyl-arginyl-4-(3-carboxy2-methyl)piperidyl]benzopiperidine]. This active site inhibitor is very potent and highly selective and the compound is adsorbed from the gastrointestinal tract.

Glycosaminoglycan polysulphates of bovine origin are semi-synthetic analogues of heparin which are virtually inactive in vitro. When given by parenteral injection the heparin analogue has almost the same potentiating effect on antithrombin III as heparin but considerably less on the activated partial clotting time. ${ }^{30}$ An ideal drug for preventing thrombosis would indeed inhibit the generation of factor $\mathrm{Xa}$ without delaying significantly the clotting time.

The future lies in finding synthetic inhibitors capable of discriminating between enzymes of closely related specificity. In view of the great number of physiologically important serine proteases continually being discovered a more precise description of the structure of their active site will hopefully enable inhibitors to be synthesised that are able to discriminate between the different serine proteases.

\section{References}

1 Donaldson VH, Evans RR. A biochemical abnormality in hereditary angioneurotic edema. Absence of serum inhibitor of $\mathrm{C}_{1}$-esterase. Am J Med 1963;35:37-44.

${ }^{2}$ Gigli I, Mason JW, Colman RW, Austen KE. Interaction of plasma kallikrein with the $\mathrm{C}_{1}$-inhibitor. $J$ Immunol 1970;104:574-81.

s Donaldson VH, Rosen FS, Bing DH. Role of the second component of complement (C2) and plasmin in kinin release in angioneurotic edema (HANE) plasma. Clin Res 1977;25:520A.

${ }^{4}$ Gelfand JA, Sherins RJ, Alling DW, Frank MM. Treatment of hereditary angioedema with danazol: reversal of clinical and biochemical abnormalities. $N$ Engl J Med 1976;295:1444-8.

${ }^{5}$ Sheffer AL, Fearon DT, Austen KF. Methyltosterone therapy in hereditary angioedema. Ann Intern Med 1977;86:306-8.

${ }^{6}$ Thompson RA, Felix-Davies DD. Response of 'idiopathic' recurrent angioneurotic oedema to tranexamic acid. $\mathrm{Br} \mathrm{Med} J$ 1978;2:608.

7 Laurberg G. Tranexamic acid (Cyklokapron) in chronic urticaria: a double-blind study. Acta Derm Venereol 1977;57:369-70.

${ }^{8}$ Nymand G, Dyerberg J. Tranexamic acid: a new approach to autoimmune disease? Lancet 1975; 2:546.

${ }^{9}$ Lazarus GS, Daniels JR, Brown RS, Bladen HA, Fullmer HM. Degradation of collagen by a human granulocyte collagenolytic system. J Clin Invest 1968;47:2622-9.

10 Janoff A. Purification of human granulocyte elastase by affinity chromatography. Lab Invest 1973; 29:458-64.

${ }^{11}$ Henson PM. The immunologic release of constituents from neutrophil leukocytes. 1 . The role of antibody and component on non-phagocytosable surfaces of phagocytosables particles. J Immunol 1971;107: 1535-57.

12 Weissmann G, Zurier RB, Spieler PJ, Goldstein IM. Mechanisms of lysosomal enzyme release from leukocytes exposed to immune complexes and other particles. J Exp Med (Suppl) 1971 ;134:149-65.

${ }^{13}$ Stambaugh R, Buckley J. Zona pellucida dissolution enzymes of the rabbit sperm head. Science 1968; $161: 585-6$.

14 Stambaugh R, Buckley J. Identification and subcellular localization of the enzymes affecting penetration of the zona pellucida by rabbit spermatozoa. $J$ Reprod Fertil 1969;19:423-32.

${ }^{15}$ Stambaugh R, Buckley J. Studies on acrosomal proteinase of rabbit spermatozoa. Biochim Biophys Acta 1972;284:473-7.

16 Williams WL. Biochemistry of capacitation of spermatozoa. In: Moghissi KS, Hafez ESE, eds. Biology of mammalian fertilization and implantation. Springfield: Charles C Thomas, 1972:19.

17 Stambaugh R, Seitz HM, Jr, Mastroianni L, Jr. Acrosomal proteinase inhibitors in rhesus monkey (Macaca mulatta) oviduct fluid. Fertil Steril 1974; 25:352-7. 
${ }^{18}$ Liedholm P, Åstedt B, Kullander S. Passage of tranexamic acid (AMCA) to semen in man and its effect on the fibrinolytic activity and on migration of spermatozoa. Fertil Steril 1973;24:517-20.

19 Duspiva W, Blümel G, Haas S, Wriedt-Lübcke I. Neue Erkenntnisse zur Anastomosierung durchtrennter peripherer Nerven. Fortschr Med 1977; 95:304-10.

${ }^{20}$ Everberg G, Henrichsen J, Gormsen J. Plasma coagulation in myringoplasty and fascialis transplantation. Lancet 1977;1:1257-8.

${ }^{21}$ Petterson S, Hedelin H, Jansson I, Teger-Nilsson A-C. Fibrin occlusion of a vesicovaginal fistula. Lancet 1979;1:933.

22 Okamoto S, Oshiba S, Mihara H, Okamoto U. Synthetic inhibitors of fibrinolysis: in-vitro and invivo mode of action. Ann NY Acad Sci 1968;146: 414-20.

${ }^{23}$ Markwardt F. Synthetic inhibitors of fibrinolysis. In: Fibrinolytics and antifibrinolytics (Handbook of experimental pharmacology, vol 46). Berlin: Springer, 1978:511-77.

24 Thorsen S. Differences in the binding to fibrin of native plasminogen and plasminogen modified by proteolytic degradation. Influence of $\omega$-amino- carboxylic acids. Biochim Biophys Acta 1975; 393:55-65.

${ }^{25}$ Wiman B, Collen D. Molecular mechanism of physiological fibrinolysis. Nature 1978;272:549-50.

${ }^{26}$ Shaw E. Synthetic protease inhibitors acting by affinity labeling. In: Reich E, Rifkin DB, Shaw E, eds. Proteases and biological control. Cold Spring Harbor NY: Cold Spring Harbor Laboratory, $1975: 455-65$.

${ }^{27}$ Kettner C, Shaw E. D-Phe-Pro-ArgCH${ }_{2} \mathrm{Cl}-\mathrm{A}$ selective affinity label for thrombin. Thromb Res 1979; 14:969-73.

${ }^{28}$ Bajusz S, Barabas E, Szell E, Bagdy D. Peptide aldehyde inhibitors of the fibrinogen-thrombin reaction. In: Walter R, Meienhofer J, eds. Peptides: Chemistry, structure and biology. Ann Arbor: Ann Arbor Science Publishers, 1975:603.

${ }^{29}$ Okamoto S, Hijikata A, Kikumoto R, Tamao Y. A synthetic thrombin inhibitor taking extremely active stereostructure (abstract). Thromb Haemostas 1979; 42:205.

${ }^{30}$ Thomas DP, Michalski R, Lane DA, Johnson EA, Kakkar VV. A heparin analogue with specific action on antithrombin III. Lancet 1977;1:120-2. 